
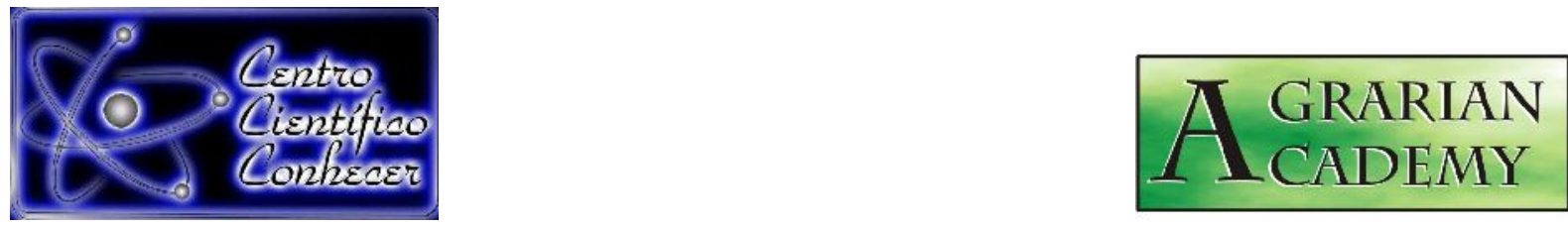

\title{
INFLUÊNCIA DO ESTRESSE HÍDRICO SOBRE O DESENVOLVIMENTO INICIAL DE MUDAS DE (VIGNA UNGUICULATA (L.) WALP.) FEIJÃO-DE-CORDA
}

\section{Elivan Custodio Araujo}

Biólogo. Universidade Estadual do Ceará - UECE - Centro de Educação, Ciências e Tecnologia da Região dos Inhamuns - CECITEC. Tauá - CE. Rua Solon Medelros, S/N- BR 020, Tauá - CE, 63660-000. Especialização em Microbiologia. Faculdade

Futura - ICETEC - Instituto de Ciência Educ. e Tecnologia de Votuporanga. Votuporanga - SP. Av. Valê do Sol, 4876 - Vale do Sol, Votuporanga - SP, 15500-269 (elivancustodio@hotmail.com).

Recebido em: 15/06/2021 - Aprovado em: 15/07/2021 - Publicado em: 30/07/2021 DOI: 10.18677/Agrarian_Academy_2021A6

\section{RESUMO}

O objetivo do presente trabalho foi avaliar a influência do déficit hídrico sobre o crescimento de mudas de feijão-de-corda. Os frutos foram obtidos em setembro de 2019. O experimento foi conduzido no Centro de Educação, Ciências e Tecnologia da Região dos Inhamuns - CECITEC, Universidade Estadual do Ceará - UECE, cidade de Tauá-Ce. As mudas foram produzidas através da semeadura direta, em copos plásticos $(200 \mathrm{~mL}$ ) utilizando $100 \mathrm{~g} / \mathrm{copo}$ de substrato. Foram feitos quatro tratamentos (T0, T1, T2 e T3) em três repetições (P1, P2 e P3). Foi realizada avaliação aos 15 dias (inicial) e 30 dias (final) para se determinar a altura, o número de folhas e tamanho das raízes com o auxílio de uma régua. $O$ déficit hídrico foi perceptível nos tratamentos T1, T2 e T3. T1 apresentou desenvolvimento vegetativo de $-2,84 \mathrm{~cm}$ para a altura das plantas; para o número foliar -2 e $-3,33 \mathrm{~cm}$ no tamanho da raiz em relação ao grupo T0. O grupo T2 apresentou $-2,84 \mathrm{~cm}$ para a altura das plantas; $-1,67$ para o número de folhas e $-3 \mathrm{~cm}$ no tamanho do cumprimento radicular com relação ao grupo T0. E o grupo T3 apresentou desenvolvimento vegetativo de $-1,54 \mathrm{~cm}$ para a altura das plantas; não ocorreu diferença entre o número de folhas (zero) e teve uma pequena variação 0,67 $\mathrm{cm}$ no tamanho da raiz das plantas em relação ao tratamento T0. Concluiu-se, portanto, que a diferença de regime hídrico exerceu efeito significativo nas variáveis estudadas, modificando o desenvolvimento das plantas.

PALAVRAS-CHAVE: Crescimento vegetativo. Plântula. Tratamento. 


\title{
INFLUENCE OF WATER STRESS ON THE INITIAL DEVELOPMENT OF SEEDLINGS OF (VIGNA UNGUICULATA (L.) WALP.) STRING BEANS
}

\begin{abstract}
The aim of the present study was to evaluate the influence of water deficit on the growth of french beans. The fruits were obtained in September 2019. The experiment was conducted at the Education, Science and Technology Center of the Inhamuns Region CECITEC, State University of Ceará - UECE, city of Tauá-Ce. The seedlings were produced by direct seeding, in plastic cups $(200 \mathrm{ml})$ using $100 \mathrm{~g} /$ cup of substrate. Four treatments (T0, T1, T2 and T3) were performed in three repetitions (P1, P2 and P3). Evaluation was performed at 15 days (initial) and 30 days (final) to determine the height, number of leaves and size of roots with the aid of a ruler. The water deficit was noticeable in the T1, T2 and T3 treatments. T1 showed vegetative development of -2.84 $\mathrm{cm}$ for the height of the plants; for the leaf number -2 and $-3.33 \mathrm{~cm}$ in the root size in relation to the T0 group. The T2 group showed $-2.84 \mathrm{~cm}$ for the height of the plants; 1.67 for the number of leaves and $-3 \mathrm{~cm}$ in the size of the root length in relation to the T0 group. And the T3 group showed vegetative development of $-1.54 \mathrm{~cm}$ for the height of the plants; there was no difference between the number of leaves (zero) and there was a small variation of $0.67 \mathrm{~cm}$ in the root size of the plants in relation to the T0 treatment. It is concluded, therefore, that the difference in water regime had a significant effect on the studied variables, modifying the development of plants.
\end{abstract}

KEYWORDS: Vegetative growth. Seedling. Treatment.

\section{INTRODUÇÃO}

A Vigna unguiculata (I.) walp (feijão-de-corda) é considerada uma planta rústica, adaptando-se às diferentes condições de clima e solo, sendo cultivada em regiões úmidas, subúmidas e semi-áridas. Distingue-se das outras por apresentar uma excelente capacidade de adaptação à seca, conquanto, essa capacidade varie entre os cultivares e os estádios de desenvolvimento (GWATHMEY; HALL, 1992).

Segundo Melo et al., (2016), o cultivo do feijoeiro tem se ampliado para várias regiões com distribuição pluvial irregular, devido à adoção de várias tecnologias, entre as quais está a irrigação, que tem como objetivo aumentar o rendimento da cultura, sendo o Brasil o segundo maior produtor e o principal consumidor mundial desse grão.

No semiárido brasileiro as plantas estão sujeitas ao estresse hídrico, devido à escassez das chuvas e a irregularidade. Silva et al., (2009) observaram que plantas cultivadas em ambientes áridos e semiáridos podem ser expostas a longos períodos de déficit de água no solo e desenvolveram adaptações para tolerar a seca. Além disso, não é apenas a precipitação que gera o déficit hídrico, todavia, a associação a outros fatores característicos da região, como altas temperaturas associadas à alta intensidade luminosa, também provoca um processo evaporativo alto e consequente dessecação do solo (TROVÃO et al., 2007).

As dessemelhantes reações de cada espécie de plantas a essas variações de déficit de água permitem que o feijão-de-corda possa tolerá-las quando em níveis críticos sustentando, ainda assim, taxas adequadas de fotossíntese (RIBEIRO et al., 
2004). Cultivares de feijão-caupi proporcionam diferentes revides fisiológicos quando submetidos a escassez de água no solo (BEZERRA et al., 2003; RIBEIRO et al., 2003).

A avaliação do déficit hídrico das plantas quando submetidas a escassez hídrica nas fases vegetativa e reprodutiva, comprova que cultivares de feijão-de-corda sofreram reduções relevantes no potencial hídrico foliar, condutividade estomática e transpiração foliar, com natural aumento na temperatura da folha (MENDES et al., 2007). Diversos parâmetros têm sido analisados para se avaliar a resposta das espécies vegetais ao estresse hídrico (COSTA et al., 1997; FERREIRA et al., 1991; PIMENTEL, COSTA, 1995; PEREZ, 2000), pois, a tolerância á escassez de água de feijão-de-corda muda com o estádio de desenvolvimento da planta.

Existem alguns estudos com o estresse hídrico em feijoeiro, e esses trabalhos têm sido conduzidos nesse sentido, como por exemplo, atenuação de estresse hídrico em plantas de feijão-caupi (COSTA, 2016), efeito da disponibilidade de água na germinação e no desenvolvimento inicial de plântulas de feijão-caupi (SILVA et al., 2013), na fase de floração: efeito do déficit hídrico na fase de enchimento de grãos do feijoeiro comum (MARTINS et al., 2017), tolerância ao déficit hídrico em genótipos de feijão-caupi (NASCIMENTO et al., 2011), entre outros trabalhos. No entanto, ainda são insuficientes as informações sobre os processos fisiológicos básicos envolvidos neste tipo de estudo, o que justifica o presente trabalho. Sendo assim, o objetivo do estudo foi avaliar a influência do déficit hídrico sobre o desenvolvimento inicial de mudas de feijãode-corda.

\section{MATERIAL E MÉTODOS}

A pesquisa do presente trabalho é de cunho quantitativo e qualitativo. Sabe-se que uma pesquisa de abordagem quali-quantitativa possibilita a análise de processos legais diante de métodos qualitativos dos métodos quantitativos com análise estrutural dos fenômenos, as pesquisas quali-quantitativa se apoiam uma pela outra (SCHNEIDER et al., 2017). Conforme Silva et al., (2017), a CAPES (Coordenação de Aperfeiçoamento de Pessoal de Nível Superior) estabelece parâmetros para a validação de uma pesquisa científica, e são: a validade (obtenção de uma resposta para um estudo), a confiabilidade (dados fidedignos) e a generalização (estudar elementos individuais e/ou grupos para formular uma hipótese que possa abranger uma população). Tais critérios são usuais às pesquisas quantitativas e qualitativas não havendo superioridade entre estas.

O estudo foi realizado no Centro de Educação, Ciências e Tecnologia da Região dos Inhamuns - CECITEC, cidade de Tauá, estado do Ceará, nordeste do Brasil localizada na Região dos Inhamuns, em 2019. O município de Tauá está a uma distância de aproximadamente $357 \mathrm{~km}$ da capital Fortaleza, obedecendo as seguintes

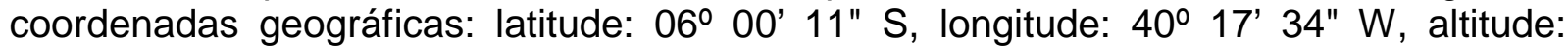
$402,7 \mathrm{~m}$ e ocupa uma área de unidade territorial de 4.010,618 km², com 59.062 habitantes, apresenta clima tropical quente semiárido, com chuvas de fevereiro a abril, relevo depressões sertanejas e maciços residuais, com vegetação de caatinga arbustiva aberta e floresta caducifólia espinhosa Precipitação pluviométrica (média em 2019) de 416,9 mm (CEARÁ, 2009; IBGE, 2020). 
O estudo foi realizado com sementes de feijão-de-corda que foram obtidas em setembro de 2019 em Tauá-Ce, referente à safra 2017/2018. Foi utilizado para o desenvolvimento da pesquisa: as sementes de feijão-de-corda, um medidor de água, seringa, copos descartáveis de $200 \mathrm{~mL}$, substratos e régua.

FIGURA 1. Sementes de Vigna unguiculata (I.) (Feijão-de-corda), medidor, seringa, copo, substrato e régua.
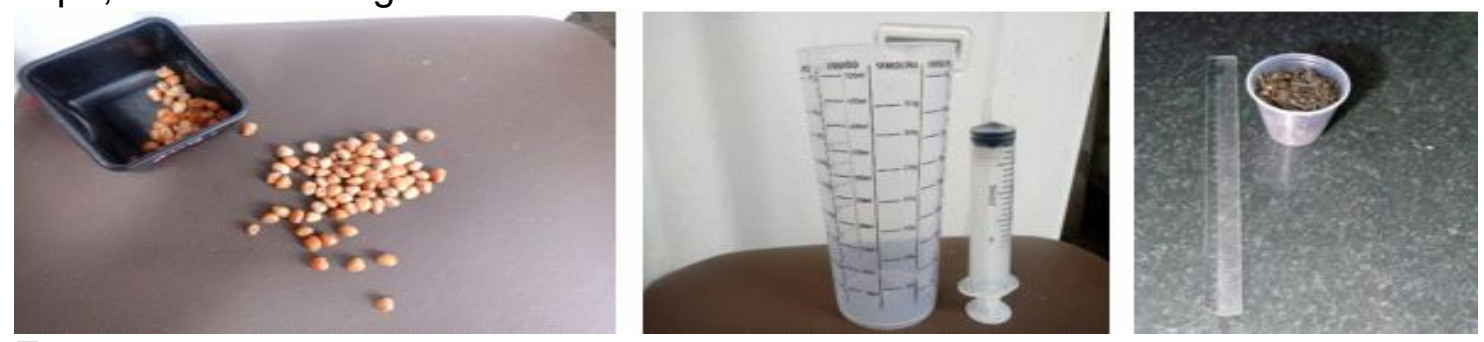

Fonte: o autor.

No plantio não houve a necessidade de fazer quebra de dormência, pois, as sementes de feijão-de-corda não apresentam essa condição germinando facilmente (MARCOS FILHO, 2005). As mudas foram produzidas através da semeadura direta, em copos plásticos $(200 \mathrm{~mL}$ ), o substrato utilizado foi terra e esterco (húmus) de animais adquirido na SUPERMATA (Superintendência Municipal do Meio Ambiente) de Tauá em uma proporção de 3:1 respectivamente. Foi feita a medição da capacidade de suporte de absorção de água que o substrato suportava no copo de $200 \mathrm{~mL}$. Observou-se que $100 \mathrm{~g}$ de resíduo num copo de $200 \mathrm{~mL}$ suporta $75 \mathrm{~mL}$ de água, isso foi observado quando colocados no copo e regado com $100 \mathrm{~mL}$ de água excedendo $25 \mathrm{~mL}$ filtrado. Foram feitos quatro tratamentos (T0, T1, T2 e T3) em três repetições (P1, P2 e P3).

Quinze dias após a germinação das sementes, todas as plântulas foram medidas e então iniciaram-se os tratamentos. Os Tratamentos foram: Grupo T0 ou Tratamento Controle $100 \%$ da capacidade de suporte de água do solo $(75 \mathrm{~mL})$ irrigado diariamente. Grupo T1 ou $50 \%$ da capacidade de suporte de água do solo $(37,5 \mathrm{~mL})$ irrigado a cada dois dias. Grupo T2 ou $25 \%$ da capacidade de suporte de água do solo $(18,75 \mathrm{~mL})$ irrigado a cada quatro dias. Grupo T3 ou 10\% da capacidade de suporte de água do solo $(7,5 \mathrm{~mL})$ irrigado a cada seis dias.

Foi realizada uma avaliação aos 15 dias (inicial) e outra aos 30 dias (final) para se determinar a altura das plantas e também da raiz com o auxílio de uma régua, bem como, a contagem do número de folhas. Na avaliação final (30 dias), foram realizadas uma avaliação destrutiva e as mudas separadas em raiz e parte aérea para novas medições e posteriormente levadas para estufa a $80^{\circ} \mathrm{C}$ por 24 horas para se avaliar a massa seca. Após a obtenção dos dados realizou-se uma análise estatística para verificar se houve efeito dos tratamentos através de uma ANOVA. Os resultados foram apresentados em tabela e gráficos confeccionados no programa Word e Excel 2019 para uma melhor elucidação dos mesmos. 


\section{RESULTADOS E DISCUSSÃO}

Embora os resultados demonstrem aumento no percentual de desenvolvimento vegetativo dentro dos grupos, fica perceptível também, um decréscimo no desenvolvimento das plantas quando comparadas ao Tratamento Controle T0 (Tabela 1). Os resultados da análise de variância para a porcentagem do desenvolvimento vegetativo do feijão-de-corda sob diferentes potenciais osmóticos apresentaram diferenças estatísticas significativas, modificando a fisiologia e o desenvolvimento das plantas. Conforme Marcos Filho, (2005), a escassez hídrica pode afetar as diferentes fases do desenvolvimento do feijão-de-corda, dentre elas o desenvolvimento inicial, pois, a água é um dos fatores que mais compromete esta fase, já que é a responsável pela ativação do metabolismo e por outras etapas envolvidas no processo no desenvolvimento da planta.

Cabe destacar que o potencial mais negativo testado no presente trabalho foi nos Tratamentos T2 e T3 (Tabela 1). Pesquisa semelhante desenvolvida por Resende et al., (1981), foi observado que houve reduções na taxa de expansão foliar de plantas de feijão-de-corda quando submetidas a estresse hídrico, em comparação a de plantas irrigadas. Resultados semelhantes foram ainda encontrados por Costa, (1995) e Turk et al., (1980) para o feijão-de-corda; Santos, (2016) e Pimentel e Perez, (2000), para o feijoeiro; e Farah, (1981) para fava. Porém, as plantas cultivadas em ambientes áridos e semiáridos, podem ser expostas a longos períodos de déficit de água no solo e desenvolverem adaptações para tolerar a seca (SILVA et al., 2009). O feijão-de corda é bem resistente ao estresse hídrico e se adapta bem em ambientes áridos e semiáridos como perceptível no trabalho.

O tratamento T0 apresentou desenvolvimento constante e progressivo em todas as vaiáveis estudadas com relação à altura $16 \mathrm{~cm}$, número foliar 8 e crescimento do sistema radicular de $13,66 \mathrm{~cm}$, irrigado diariamente. O tratamento $\mathrm{T} 1$ aos 30 dias teve desenvolvimento vegetativo de $14,46 \mathrm{~cm}$ na altura, 8 no número foliar e $14,33 \mathrm{~cm}$ no sistema radicular quando comparada as primeiras observações feita no 15 일. Porém, quando comparados os tratamentos $\mathrm{T} 1$ que foi irrigado a cada dois dias com o tratamento controle ou T0 controle, houve um déficit de: $-1,54$ na altura das mudas, não houve diferença no número foliar (zero) e um aumento no sistema radicular de $0,67 \mathrm{~cm}$ (Tabela 1). O déficit hídrico foi mais perceptível nos tratamentos T2 e T3. O tratamento T2 foi irrigado a cada quatro dias e o tratamento T3 foi irrigado a cada seis dias. O tratamento T2 aos 30 dias apresentou desenvolvimento vegetativo de $13,16 \mathrm{~cm}$ na altura, 6,33 no número foliar e $10,66 \mathrm{~cm}$ no sistema radicular quando comparado ao $15^{\circ}$ dia quando foram feitas as primeiras observações. Quando comparados os tratamentos T2 com o controle ou T0 controle houve um déficit no desenvolvimento vegetativo das plântulas de: $-2,84 \mathrm{~cm}$ para a altura, $-1,67$ para o número foliar e $-3 \mathrm{~cm}$ no sistema radicular (Tabela 1). O tratamento T3 também apresentou desenvolvimento vegetativo aos 30 dias quando comparados as primeiras anotações feitas no $15^{\circ}$ dia de $13,16 \mathrm{~cm}$ na altura, 6 no número foliar e 10,33 cm no sistema radicular. Houve uma diferença significativa no desenvolvimento vegetativo das mudas entre o tratamento T3 e tratamento controle ou T0. As plântulas apresentaram um déficit de $-2,84 \mathrm{~cm}$ para a altura, -2 no número foliar e $-3,33$ no sistema radicular (Tabela 1). 
A diferença de regime hídrico exerceu efeito nas variáveis estudadas, modificando o desenvolvimento das mudas, porém, é notório que o feijão-de-corda é muito resistente a escassez hídrica (Tabela 1). Contudo pesquisadores como Trovão et al., (2007), acrescentam ainda que, não é apenas a precipitação que gera o déficit hídrico, todavia, a associação a outros fatores característicos da região, como altas temperaturas associadas à alta intensidade luminosa, também provoca um processo evaporativo alto e consequente dessecação do solo. Esses fatores são bem característicos do bioma caatinga e modificam a fisiologia e desenvolvimento das plantas nesse ambiente, especialmente o feijão-de-corda, que é tão utilizado como meio de cultura na região nordeste do Brasil.

TABELA 1. Avaliação inicial, final e do desenvolvimento vegetativo das plântulas de Vigna unguiculata (I.) (Feijão-de-corda) nos tratamentos T0 (75 mL); T1 (37,5 mL); T2 $(18,5 \mathrm{~mL})$ e T3 $(10 \mathrm{~mL})$

\begin{tabular}{|c|c|c|c|}
\hline \multicolumn{4}{|c|}{ T0 Avaliação inicial sem tratamento (15 dias), irrigadas diariamente (75 ml) } \\
\hline Plantas & Altura $(\mathrm{cm})$ & № de folhas & Raízes (cm) \\
\hline P1 & 12,5 & 5 & - \\
\hline P2 & 11,4 & 5 & - \\
\hline P3 & 4 & 5 & - \\
\hline \multicolumn{4}{|c|}{ T0 Avaliação final sem tratamento (30 dias), irrigadas diariamente (75 ml) } \\
\hline P1 & 17 & 8 & 18 \\
\hline P2 & 17,5 & 8 & 13 \\
\hline P3 & 13,5 & 8 & 10 \\
\hline *Média Final & 16 & 8 & 13,66 \\
\hline \multicolumn{4}{|c|}{ T1 Avaliação inicial (15 dias). Tratamento: irrigadas a cada dois dias (37,5 ml) } \\
\hline Plantas & Altura $(\mathrm{cm})$ & № de folhas & Raízes (cm) \\
\hline P1 & 11 & 5 & - \\
\hline P2 & 9,9 & 5 & - \\
\hline P3 & 7,2 & 5 & - \\
\hline \multicolumn{4}{|c|}{ T1 Avaliação final (30 dias). Tratamento: irrigadas a cada dois dias $(37,5 \mathrm{ml})$} \\
\hline P1 & 15,8 & 8 & 11 \\
\hline P2 & 14,3 & 8 & 11 \\
\hline P3 & 13,3 & 8 & 21 \\
\hline *Média Final & 14,46 & 8 & 14,33 \\
\hline ** Diferença (T1-T0) & $-1,54$ & 0 & 0,67 \\
\hline \multicolumn{4}{|c|}{ T2 Avaliação inicial (15 dias). Tratamento: irrigadas a cada quatro dias (18,5 ml) } \\
\hline Plantas & Altura (cm) & № de folhas & Raízes (cm) \\
\hline P1 & 8 & 5 & - \\
\hline P2 & 8 & 5 & - \\
\hline P3 & 9,5 & 5 & - \\
\hline \multicolumn{4}{|c|}{ T2 Avaliação final (30 dias). Tratamento: irrigadas a cada quatro dias (18,5 ml) } \\
\hline P1 & 12 & 6 & 6 \\
\hline P2 & 13,5 & 5 & 11,5 \\
\hline P3 & 14 & 8 & 14,5 \\
\hline *Média final & 13,16 & 6,33 & 10,66 \\
\hline
\end{tabular}




\begin{tabular}{|c|c|c|c|}
\hline${ }^{* \star}$ Diferença (T2-T0) & $-2,84$ & $-1,67$ & -3 \\
\hline \multicolumn{2}{|c|}{ T3 Avaliação inicial (15 dias). Tratamento: irrigadas a cada seis dias (7,5 ml) } \\
\hline Plantas & Altura (cm) & No de folhas & Raízes (cm) \\
\hline P1 & 12,5 & 5 & - \\
\hline P2 & 10.5 & 5 & - \\
\hline P3 & 7 & 5 & - \\
\hline T3 Avaliação final (30 dias). Tratamento: irrigadas a cada seis $(7,5$ ml) \\
\hline P1 & 16 & 6 & 13 \\
\hline P2 & 12 & 4 & 8,5 \\
\hline P3 & 11,5 & 8 & 9,5 \\
\hline *Média Final & 13,16 & 6 & 10,33 \\
\hline${ }^{* *}$ Diferença (T3-T0) & $-2,84$ & -2 & $-3,33$ \\
\hline
\end{tabular}

Legenda: *Média Final Equação $=\mathrm{MF} ;{ }^{* \star}$ Diferença no Desenvolvimento Vegetativo das plantas nos tratamentos DGV $=\mathrm{MF}(\mathrm{TX})-\mathrm{MF}(\mathrm{TO})=\mathrm{DGV}$, onde $(\mathrm{Tx})$, é a média estudada das variáveis (T1, T2 e T3) e (T0) é o Tratamento Controle.

Fonte: o autor.

O gráfico 1 identifica a massa seca $(\mathrm{mg})$ parte aérea e massa seca $(\mathrm{mg})$ da raiz nos grupos T0, T1, T2 e T3. Não houve diferença significativa na massa seca da parte aérea das plântulas nos tratamentos. Porém, houve um aumento na parte seca da raiz no T1 de $0,7 \mathrm{mg}$ em relação ao T0 aos 30 dias, quando foi feita a avaliação final das plântulas. Essa pequena diferença, sugere que, em condições de deficiência hídrica, a maior alocação de fotoassimilados se concentra no sistema radicular. Segundo Taiz e Zeiger, (2009), em condições de escassez hídrica, a maior alocação de fotoassimilados (compostos resultantes da fotossíntese) advém das raízes, o que indica uma priorização da alocação de recursos para o aumento do sistema radicular, o que pode sobrepor a absorção de água indicando uma priorização do crescimento radicular, favorecendo a absorção de água.

GRÁFICO 1. Massa seca $(\mathrm{mg})$ parte aérea e massa seca $(\mathrm{mg})$ da raiz.

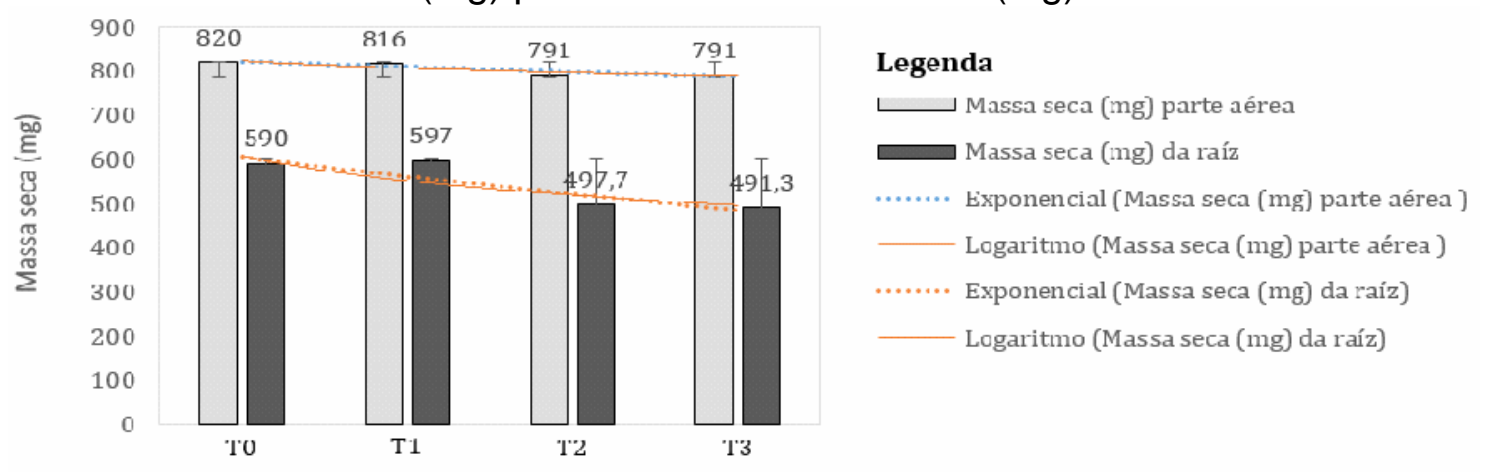

Fonte: o autor.

A figura 2 e o gráfico 2 identificam o Tratamento Controle ou T0. As plântulas apresentaram aumento constante e progressivo no desenvolvimento vegetativo aos 30 
dias em relação ao $15^{\circ}$ dia. Altura de $41,86 \%$, número de folhas $37,5 \%$ e uma média de $13,66 \mathrm{~cm}$ sistema radicular.

FIGURA 2(A). T0 ou $100 \%$ com a capacidade para $100 \mathrm{~g}$ de substrato $(75 \mathrm{~mL})$. FIGURA 2(B). Parte aérea e radicular de Vigna unguiculata (I.) (Feijão-de-corda) na fase final do experimento.
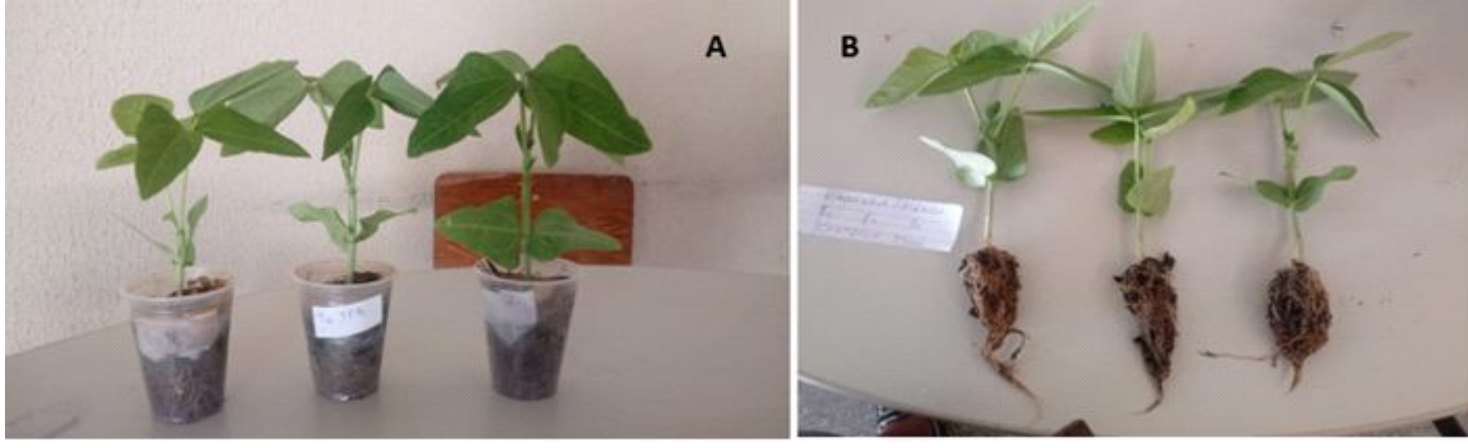

Fonte: o autor.

GRÁFICO 2. Média e desenvolvimento vegetativo das plântulas no Tratamento Controle (T0) ou $100 \%$, irrigados com $75 \mathrm{~mL}$ diariamente.

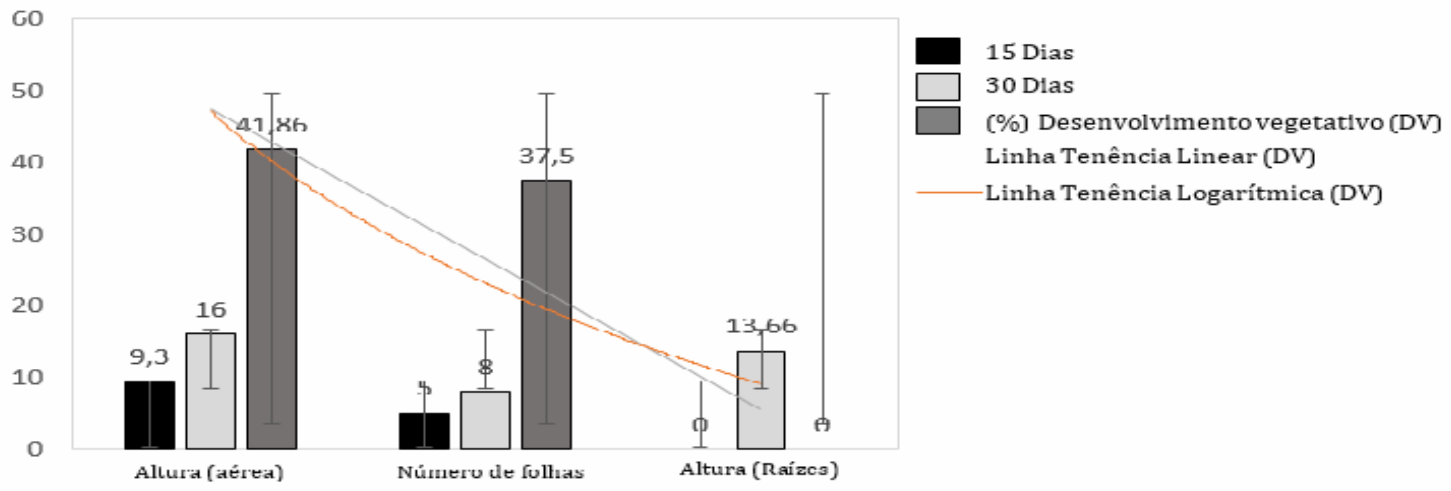

Fonte: o autor.

A figura 3 e gráfico 3 mostra o Tratamento T1. Foi observado aos 30 dias que as mudas tiveram um aumento vegetativo de $35,27 \%$ na altura das plântulas. Em relação ao número foliar o grupo apresentou aumento de 33,33\% e uma média de 14,33 cm no sistema radicular das mudas. O déficit hídrico causou uma diminuição no desenvolvimento vegetativo entre os tratamentos T1 e T0 de $-1,54 \mathrm{~cm}$ para a altura; 0 (zero) para o número foliar e um aumento de $0,67 \mathrm{~cm}$ no tamanho do sistema radicular (tabela 1). Segundo Taiz e Zeiger, (2009), a redução do número foliar nas plantas durante períodos de estresse é uma adequação que reduz a área de perda de água das plantas e em condições de deficiência hídrica, as plantas priorizam o desenvolvimento do sistema radicular, para aumentar a captação de recursos. 
FIGURA 3(A). T1 ou 50\% com a capacidade para $100 \mathrm{~g}$ de substrato $(37,5 \mathrm{~mL})$. FIGURA 3(B). Parte aérea e radicular de Vigna unguiculata (I.) (Feijão-de-corda).
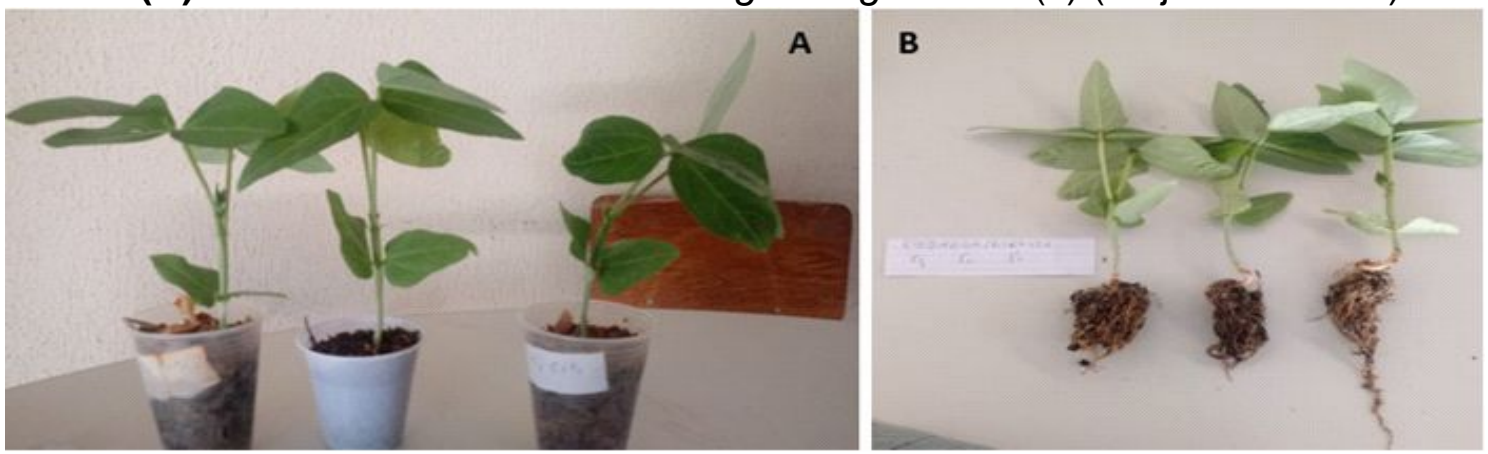

Fonte: 0 autor.

GRÁFICO 3. Média e desenvolvimento vegetativo das plântulas no Tratamento 2 (T1) ou $50 \%$, irrigadas a cada dois dias com $37,5 \mathrm{ml}$.

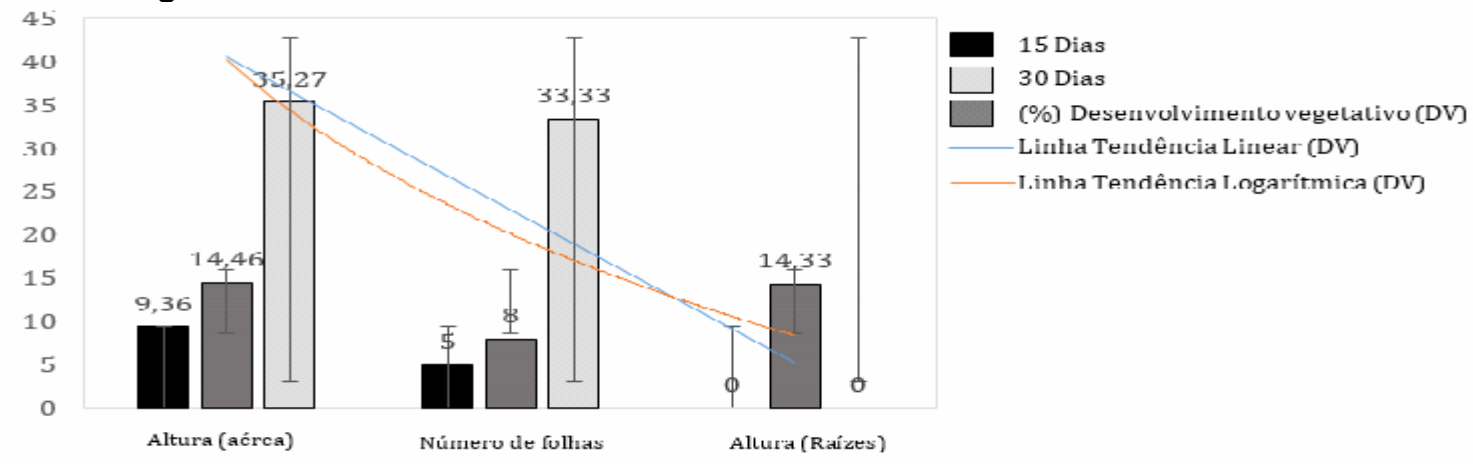

Fonte: o autor.

A figura 4 e gráfico 4 mostra o Tratamento T2. O grupo apresentou um desenvolvimento vegetativo de $35,41 \%$ na altura, $21,01 \%$ no número foliar das plântulas e uma média de $10,66 \mathrm{~cm}$ no sistema radicular das mudas quando comparadas às primeiras anotações feitas no $15^{\circ}$ dia. $O$ experimento mostrou uma diferença no desenvolvimento vegetativo entre os tratamentos T2 e T0 de $-2,84 \mathrm{~cm}$ para a altura; $-1,67$ para o número de folhas e $-3 \mathrm{~cm}$ no tamanho da raiz (tabela 1).

FIGURA 4(A). T2 ou $25 \%$ com a capacidade para $100 \mathrm{~g}$ de substrato $(18,75 \mathrm{~mL})$. FIGURA 4(B). Parte aérea e radicular de Vigna unguiculata (I.) (Feijão-de-corda).
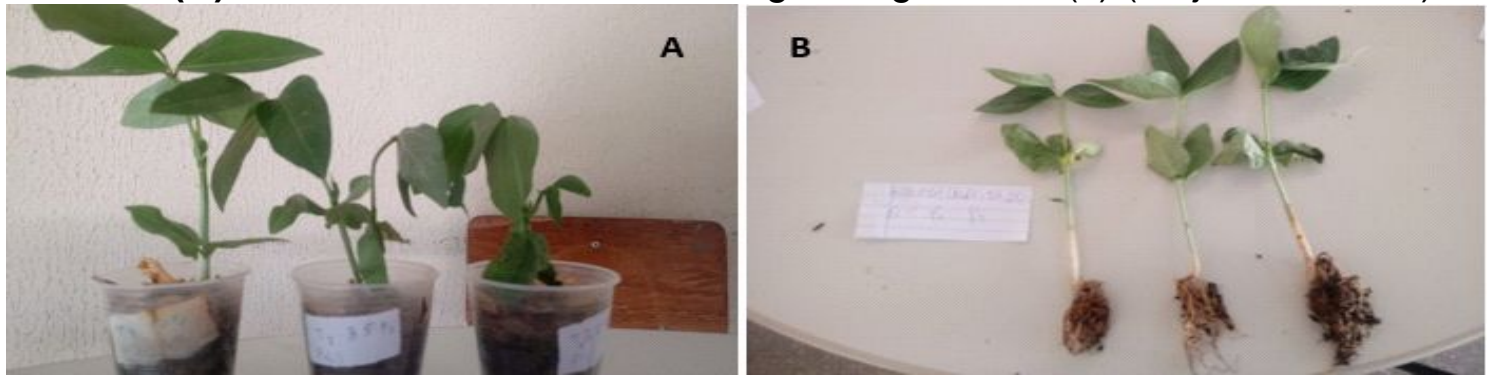

Fonte: 0 autor. 
GRÁFICO 4. Média e desenvolvimento vegetativo das plântulas no Tratamento 3 (T2) ou $25 \%$, irrigadas a cada 4 dias com $18,75 \mathrm{~mL}$.

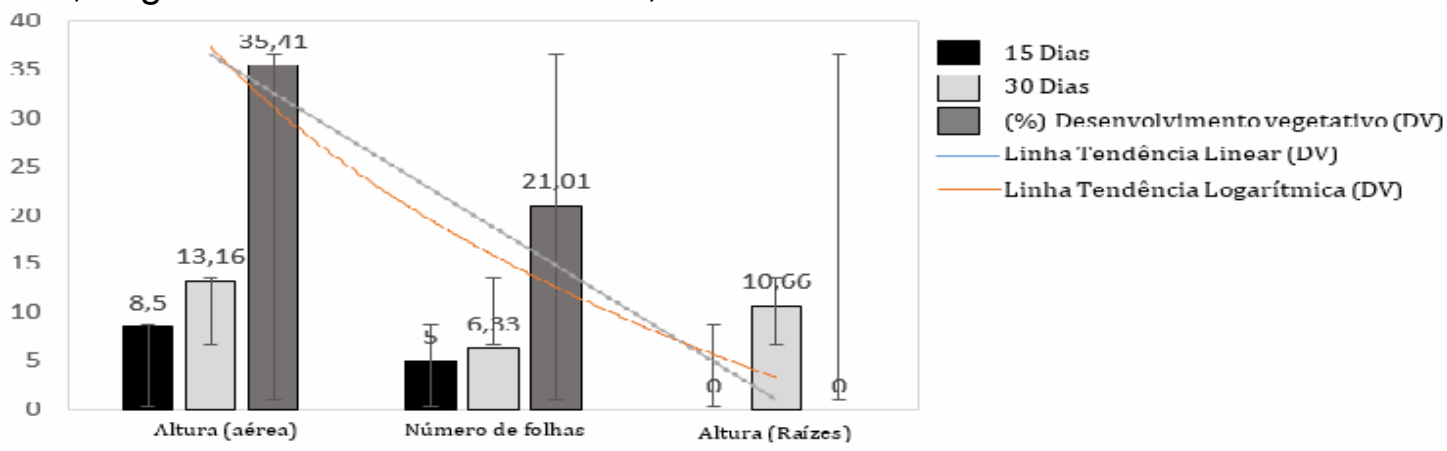

Fonte: 0 autor.

A figura 5 e gráfico 5 identifica o Tratamento T3, aos 30 dias apresentou um desenvolvimento vegetativo de $27,35 \%$ na altura das plântulas, 16,66 \% no número de folhas e uma média de $10,33 \mathrm{~cm}$ no sistema radicular em comparação as primeiras observações feitas no $15^{\circ}$ dia. A diferença do desenvolvimento vegetativo entre os tratamentos T3 e T0 foi de $-2,84 \mathrm{~cm}$ para a altura; -2 para o número de folhas e $-3,33$ $\mathrm{cm}$ no sistema radicular (tabela 1).

FIGURA 5(A). T3 ou $10 \%$ com a capacidade para $100 \mathrm{~g}$ de substrato $(7,5 \mathrm{ml})$. FIGURA 5(B). Parte aérea e radicular de Vigna unguiculata (I.) (Feijão-de-corda).

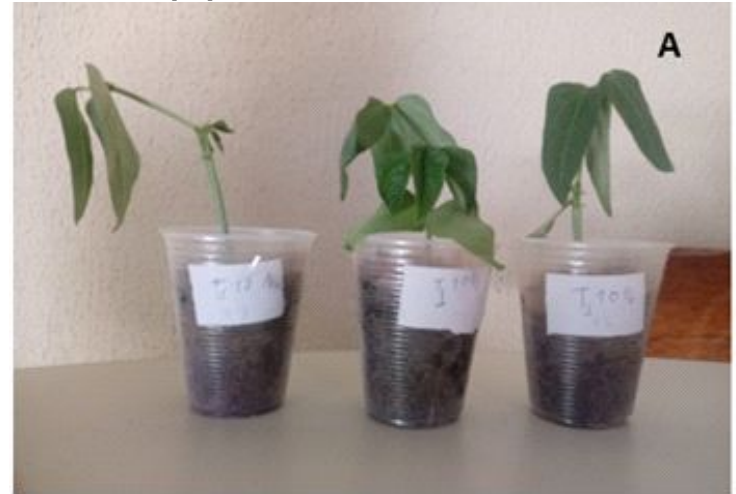

B

Fonte: o autor. 
GRÁFICO 5. Média e desenvolvimento vegetativo das plântulas no Tratamento 3 (T3) ou $10 \%$, irrigadas a cada 6 dias com $7,5 \mathrm{~mL}$.

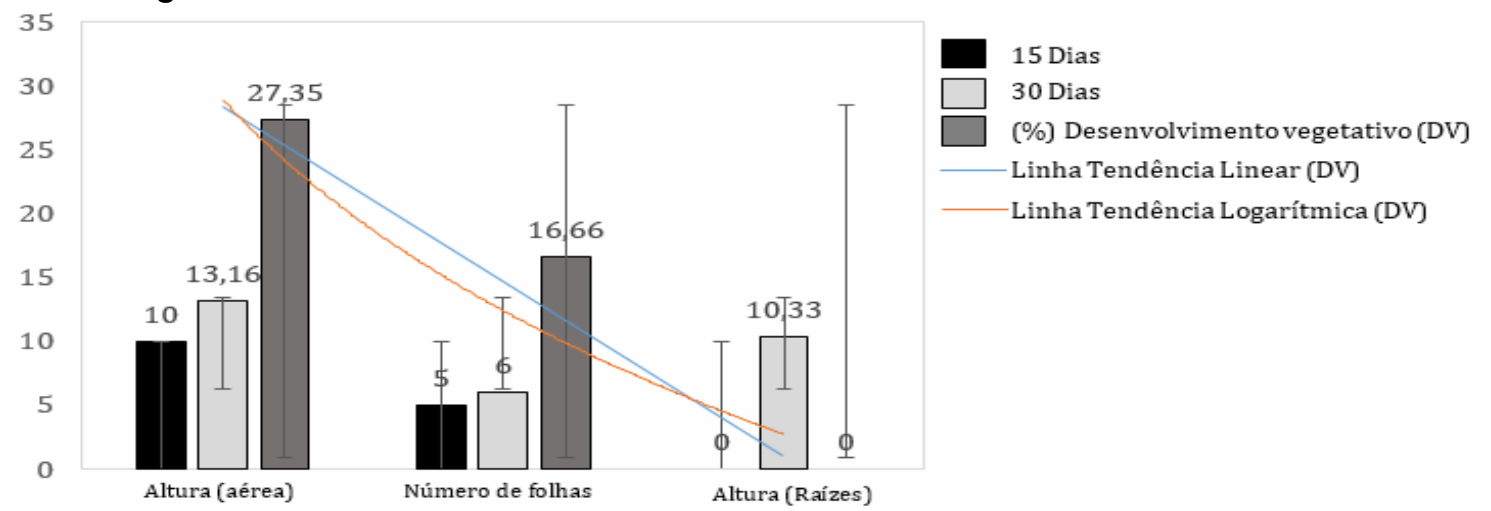

Fonte: o autor.

\section{CONCLUSÃO}

O estresse hídrico exerceu efeito significativo nas variáveis estudadas no experimento, alterando o desenvolvimento vegetativo das mudas de feijão-de-corda, pois, as plântulas apresentaram efeito morfológico durante todas as avaliações: na altura, no número foliar e no sistema radicular. Conclui-se, portanto, que a alteração no sistema radicular das plantas é uma forma de elas aumentarem a captação de recursos e a redução especialmente no número foliar durante os períodos de escassez hídrica é uma adaptação da mesma que reduz a área de perda de água das plantas. Sendo assim, o déficit hídrico é um fator abiótico que afeta diretamente o desenvolvimento das plantas, provocando alterações morfológicas.

\section{AGRADECIMENTOS}

Ao prefeito Monteiro Filho (Prefeitura Municipal de Arneiroz) e a Paz Loureiro (Coordenador do Programa Bolsa Universitária de Arneiroz) pelo apoio no desenvolvimento da pesquisa.

\section{REFERÊNCIAS}

BEZERRA, F. M. L.; ARARIPE, M. A. E.; TEÓFILO, E. M.; CORDEIRO, L. G.; SANTOS, J. J. A. Feijão-caupi e déficit hídrico em suas fases fenológicas. Ciência Agronômica, v.34, p.5-10, 2003. Disponível em: $<$ http://webcache.googleusercontent.com/search?q=cache:cY8Rp-

IYddMJ:www.ccarevista.ufc.br/site/down.php\%3Farq\%3D02rca34-1. pdf+\&cd=1\&hl=ptBR\&ct=clnk\&gl=br>.

CEARÁ, Instituto de Pesquisa e Estratégia Econômica do Ceará. IPECE. Disponível em:<https://www.ipece.ce.gov.br/wpcontent/uploads/sites/45/2018/09/Taua_2009.pdf>.

COSTA, M. M. M. N. Comportamento de cultivares de caupi submetidas a deficiência hídrica em duas fases do ciclo fenológico. 1995. 66f. Dissertação 
(Mestrado em Fitotecnia) - Universidade Federal do Ceará, Fortaleza. Disponível em: <http://www.repositorio.ufc.br/handle/riufc/31693>.

COSTA, M. M. M. N.; TÁVORA, F. J. A. F.; PINHO, J. L. D. de.; MELO, F. I. O. Produção, componentes de produção, crescimento e distribuição das raízes de caupi submetido à deficiência hídrica. Pesquisa Agropecuária Brasileira, Brasilia, v.2, n.1, p.43-50, jan. 1997. Disponível em: $<$ https://seer.sct.embrapa.br/index.php/pab/article/view/4605>.

COSTA, R. R. da. Atenuação de estresse hídrico em plantas de feijão caupi tratadas com ácido salicílico. 2016. Dissertação (Mestrado) - Programa de PósGraduação em Ciências Agrárias da Universidade Estadual da Paraíba/Embrapa Algodão. 2016. Disponível em: <http://tede.bc.uepb.edu.br/jspui/handle/tede/2413>.

FARAH, S.M. An examination of the effects of water stress on leaf growth of crops of field beans (Vicia faba L.):2. Mineral content. The Journal of Agricultural Science, v.96, n.2, p.337-346. $1981 . \quad$ Disponível em: $<$ https://www.cambridge.org/core/journals/journal-of-agricultural-science/article/abs/anexamination-of-the-effects-of-water-stress-on-leaf-growth-of-crops-of-field-beans-viciafaba-l2-mineral content/45E9EA8DD6D11B0FC42CE9F4C9F80B5E\#access-block>. Doi:10.1017/S0021859600066120.

FERREIRA, L. G. R.; COSTA, J. O.; ALBUQUERQUE, I. M. de. Estresse hídrico nas fases vegetativa e reprodutiva de dois cultivares de caupi. Pesquisa Agropecuária Brasileira, Brasilia, v.26, n.7, p.1049-1055, jul. 1991. Disponível em: <https://ainfo.cnptia.embrapa.br/digital/bitstream/AI-SEDE/20974/1/pab15_jul_91.pdf>.

GWATHMEY, C. O.; HALL, A.E. Adaptation to midseason drought of cowpea genotypes with contrasting senescence traits. Crop Science, v.32, n.3, p.773-778, maio. 1992. Disponível em: <https://doi.org/10.2135/cropsci1992.0011183X003200030039>. DOI:10.2135/cropsci1992.0011183X003200030039

IBGE, Instituto Brasileiro de Geografia e Estatística. Tauá. 2020. Disponível em: <https://cidades.ibge.gov.br/brasil/ce/taua/panorama>. Acesso em: 11 jul. 2020.

MARCOS FILHO, J. Fisiologia de sementes de plantas cultivadas. Piracicaba: FEALQ, 2005. p. 495.

MARTINS, C. A. S. da.; REIS, E. F. dos.; GARCIA, G. O de; TOMAZ, M. A. Efeito do déficit hídrico na fase de enchimento de grãos do feijoeiro comum. Nativa, Sinop, v.5, n.6, p.386-395, dez. 2017. Disponível em: <http://dx.doi.org/10.5935/23187670.v05n06a02>. DOI: 10.5935/2318-7670.v05n06a02.

MELO, C. O. de.; SILVA, G. H. da.; ESPERANCICNI, M, S. T. Causalidade de preços do feijão de cor no Paraná. Revista de Política Agrícola, v. 25, n. 2, p.5-13, Jun. 2016. Disponível em: <https://seer.sede.embrapa.br/index.php/RPA/article/view/1106/998>. 
MENDES, R. M. S. de.; TÁVORA, F. J. A. F.; PITOMBEIRA. J. B.; NOGUEIRA, R. J. M. C. Relações fonte-dreno em feijão-de-corda submetido à deficiência hídrica. Revista Ciência Agronômica, Fortaleza (CE), v.38, p.95-103, nov. 2007. Disponível em: <http://ccarevista.ufc.br/seer/index.php/ccarevista/article/view/158/152>.

NASCIMENTO, S. P. do.; BASTOS, E. A.; ARAÚJO, E. C. E.; FILHO, F. R. F.; SILVA, E. M. da. Tolerância ao déficit hídrico em genótipos de feijão-caupi. Revista Brasileira de Engenharia Agrícola Ambiental, Campina Grande-PB, v.15, n.8, p.853-860, jun. 2011. Disponível em: <https://doi.org/10.1590/S1415-43662011000800013. DOI: 10.1590/S1415-43662011000800013

PIMENTEL, C.; PEREZ, C. Jerônimo, A. de La. Estabelecimento de parâmetros para avaliação de tolerância à seca, em genótipos de feijoeiro. Pesquisa Agropecuária Brasileira, v.35, n. 1, p. 31-39, jan. 2000. Disponível em: <https://doi.org/10.1590/S0100-204X2000000100005>. DOI: 10.1590/S0100204X2000000100005

RESENDE, M.; HENDERSON, D. W.; FERERES, E. Freqüência de irrigação, desenvolvimento e produção do feijão Kidney. Pesquisa Agropecuária Brasileira, v.16, n.3, p.363-370, mar. 1981. Disponível em: <https://seer.sct.embrapa.br/index.php/pab/article/view/16934/11258>.

RIBEIRO, N. D.; SILVA, S. M.; GARCIA, D. C.; JÚNIOR, L. H. Variabilidade genética para absorção de água em grãos de feijão. Pesquisa Agropecuária Gaúcha, v.9, n.12, p. 77-83, maio. 2003.2 Disponível em: <http://www.fepagro.rs.gov.br/upload/1398800207_art09.pdf>.

RIBEIRO, R. V.; SANTOS, M. G. dos.; SOUZA, G. M.; MACHADO, E. C.; OLIVEIRA, R. F. de.; ANGELOCCI, L. R.; PIMENTEL, C. Environmental effects on photosynthetic capacity of bean genotypes. Pesquisa Agropecuária Brasileira, Brasília, v.39, n.7, p.615-623, jul. 2004. Disponível em: <https://doi.org/10.1590/S0100204X2004000700001>. DOI: 10.1590/S0100-204X2004000700001.

SANTOS, P. L. S. de. Respostas fisiológicas do feijão-caupi submetidos a restrição hídrica e aplicação de óxido de cálcio sobre as folhas. 2016. 44f. Dissertação (Mestrado em Agricultura e Biodiversidade) - Universidade Federal de Sergipe. Disponível em: <https://ri.ufs.br/bitstream/riufs/3026/1/PATRICIA_LIMA_SOUZA_SANTOS.pdf>.

SCHNEIDER, E. M.; FUJII, R.A.X.; CORAZZA, M.J. Pesquisas quali-quantitativas: contribuições para a pesquisa em ensino de ciências. Revista Pesquisa Qualitativa. São Paulo (SP), v.5, n.9, p. 569-584, dez. 2017. Disponível em: $<$ https://editora.sepq.org.br/rpq/article/view/157/100>.

SILVA, E. C.; R. NOGUEIRA, J. M. C.; VAlE, F. H. A.; ARAÚJO, F. P. de.; Pimenta, M. A. Stomatal changes induced by intermittent drought in four umbu tree genotypes. 
Brazilian Journal Plant Physiology, v. 21, n. 1, p. 33-42, 2009. Disponível em: <https://doi.org/10.1590/S1677-04202009000100005>. DOI: 10.1590/S167704202009000100005.

SILVA, L. V. B. da.; MONTE, M. J. do.; GALVÃO, N. M. S. dos.; CORREIA, J. J. A. Características Qualitativas da Pesquisa Científica: Uma visão para pesquisas qualitativas e quantitativas. Id On Line Rev. Multidisciplinar e de Psic, v. 11, n. 35, p. 607-614, maio. 2017. ISSN 1981-1179 Ed. Eletrônica. Disponível em: <https://idonline.emnuvens.com.br/id/article/view/590/1068>.

DOI:10.14295/idonline.v11i35.590.

SILVA, W. C.; PEREIRA, J.S.; TELES, V. O.; CAMARA, F. T. da. Efeito da disponibilidade de água na germinação e no desenvolvimento inicial de plântulas de feijão-caupi. Enciclopédia Biosfera, Centro Científico Conhecer - Goiânia, v.9, n.16, p. 2984- 2993. Jul. 2013.2 Disponível em: <https://www.conhecer.org.br/enciclop/2013a/agrarias/efeito\%20da\%20disponibilidade. pdf>.

TAIZ, L.; ZEIGER, E. Fisiologia vegetal. 4.ed. Porto Alegre: Artmed, p.819.2009.

TROVÃO, D. M. B. M. de.; FERNANDES, P. D.; ANDRADE, L. A. de.; NETO, J. D. Variações sazonais de aspectos fisiológicos de espécies da Caatinga. Revista Brasileira de Engenharia Agrícola Ambiental, Campina Grande, v.11, n.3, p.307311, jan. 2007. Disponível em: <https://www.scielo.br/pdf/rbeaa/v11n3/a10v11n3>.

TURK, K. J.; HALL, A. E.; ASBELL, CW. Drougth adaptation of cowpea. I. Influence of drougth on seed yield. Agronomy Journal, v. 72, p. 413-420, 1980. Disponível em: $<$ https://doi.org/10.2134/agronj1980.00021962007200030004x>. 10.2134/agronj1980.00021962007200030004x 